\title{
EFICÁCIA DA MENSAGEM PRIVADA NA MEDIAÇÃO ON-LINE ${ }^{1}$
}

\author{
Denise Maria de Paiva Bertolucci \\ Doutora em Letras - Faculdade de Tecnologia de Ourinhos, Faculdade de \\ Tecnologia do Estado de São Paulo - FATEC \\ denise.bertolucci@fatecourinhos.edu.br
}

\section{RESUMO}

Este artigo traz algumas reflexões sobre o uso do recurso da mensagem privada no ambiente virtual de aprendizagem da disciplina Inglês, no curso Gestão Empresarial - EaD, da Faculdade de Tecnologia do Estado de São Paulo - FATEC. O objetivo é destacar a eficácia dessa forma de comunicação entre alunos e docentes na plataforma Moodle, considerando o papel crucial da linguagem escrita na interação com o aprendiz da modalidade de ensino em foco. Utiliza-se como metodologia de pesquisa o relato de experiência, já que a exposição se baseia na docência em EaD desenvolvida ao longo dos últimos cinco anos por esta pesquisadora, como mediadora on-line (tutora) e responsável pelas disciplinas Inglês I, Inglês II e Inglês III no curso a distância referido. A experiência indicou que, movidos por falsas crenças sobre o processo de aquisição da língua inglesa, os aprendizes, de modo geral, se sentem pouco à vontade para compartilhar suas dúvidas e sugestões abertamente. Assim, é sempre reduzida a adesão deles ao fórum e maior a aceitação das mensagens privadas. A plataforma Moodle permite que as mensagens sejam trocadas em tempo real ou não, e a interação acontece somente entre o docente e o aluno. Demonstra-se que o recurso é eficaz na mediação on-line por estas razões: o aluno sente-se resguardado para manifestar-se e participar da disciplina, permitindo que o docente o conduza à aprendizagem. Tomamse os textos de Catley LIMA; Michelle MACHADO (2010) e Ana Tinoco CABRAL; Alessandra CAVALCANTE (2010) como apoio para a discussão acerca da importância da escrita na educação a distância, e o de Fabio MADEIRA (2019), para a discussão das falsas crenças sobre o aprendizado da língua inglesa.

Palavras-chave: EaD. Ambiente virtual de aprendizagem. Mensagem privada.

\section{EFFECTIVENESS OF PRIVATE MESSAGE IN ON-LINE MEDIATION}

\section{ABSTRACT}

This paper provides some reflections on the use of private messages in the virtual learning environment of the English discipline, in the Business Management - DE

${ }^{1}$ Este artigo é a versão expandida de uma comunicação oral apresentada no VII Simpósio de Educação Inclusiva e Adaptações/ V Simpósio Internacional de Educação a Distância. São Paulo, UNESP, 2019. 
(Distance Education) course, of the Faculty of Technology of the State of São Paulo - FATEC. The goal is to highlight the effectiveness of this form of communication between students and teachers on the Moodle platform, considering the crucial function of written language in the interaction with the learner of the teaching modality in focus. It is used the experience report as research methodology, since this work is based on the teaching in distance education developed over the last five years by this researcher, as a mediator (tutor) and responsible for the English discipline (I, II and III) in the referred distance learning course. Experience has indicated that, driven by false beliefs about the process of English language acquisition, learners generally feel uncomfortable sharing their doubts and suggestions openly. Therefore, their participation in the forum is always reduced and the acceptance of private messages is higher. The Moodle platform allows messages to be exchanged in real time or not and interaction happens only between teacher and student. The resource is shown to be effective in on-line mediation for these reasons: the student feels protected to speak up and participate in the discipline, allowing the teacher to lead him/her to learning. The texts of Catley LIMA; Michelle MACHADO (2010) and Ana Tinoco CABRAL; Alessandra CAVALCANTE (2010) are taken as support for the discussion about the importance of writing in distance education, and the text by Fabio MADEIRA (2019), for the discussion about false beliefs in English language learning.

Keywords: Distance Education (DE). Virtual learning environment. Private message.

\section{EFICACIA DEL MENSAJE PRIVADO EM LA MEDIACIÓN EN LÍNEA}

\section{RESUMEN}

Este artículo trae algunas reflexiones sobre el uso del recurso de mensajes privados en el entorno del aprendizaje virtual de la asignatura de inglés, en el curso deAdministración de Empresas - Aprendizaje a distancia, en la Facultad de Tecnología del Estado de São Paulo - FATEC. El objetivo es resaltar la efectividad de esta forma de comunicación entre estudiantes y profesores en la plataforma Moodle, considerando el papel crucial del lenguaje escrito en la interacción con el alumno de la modalidad de enseñanza en foco. El informe de experiencia se utiliza como metodología de investigación, ya que la exposición se basa en la enseñanza en educación a distancia, desarrollada en los últimos cinco años por este investigador, como mediador en línea (tutor) y responsable de las asignaturas Inglés I, Inglés II y Inglés III en el referido curso a distancia. La experiencia ha demostrado que, impulsados por creencias falsas sobre el proceso de adquisición del idioma inglés, los alumnos, en general, se sienten incómodos al compartir abiertamente sus dudas y sugerencias. Por lo tanto, su participación en el 
foro siempre se reduce y la aceptación de mensajes privados es mayor. La plataforma Moodle permite intercambiar mensajes en tiempo real o no, y la interacción se lleva a cabo solo entre el profesor y el alumno. Se demuestra que el recurso es efectivo en la mediación en línea por estas razones: el estudiante se siente protegido para manifestarse y participar en la asignatura, lo que permite que el maestro lo guíe al aprendizaje. Se toman los textos de Catley LIMA; Michelle MACHADO (2010) y Ana Tinoco CABRAL; Alessandra CAVALCANTE (2010) como apoyo para la discusión sobre la importancia de la escritura en la educación a distancia, y la de Fabio MADEIRA (2019), para la discusión de creencias falsas sobre el aprendizaje del idioma inglés.

Palabras clave: Educación a distancia. Ambiente de aprendizaje virtual. Mensaje privado.

\section{INTRODUÇÃO}

A ideia para a elaboração do presente artigo é fruto da experiência desta pesquisadora com a educação a distância da Faculdade de Tecnologia do Estado de São (FATEC) desde 2014, atuando no curso Gestão Empresarial - EaD como mediadora on-line e responsável pelas disciplinas Inglês I, Inglês II e Inglês III. Ao longo desse período, imensos desafios foram enfrentados e muitas descobertas feitas. Um dos primeiros desafios foi minimizar a sensação de solidão normalmente experimentada pelo aluno de EaD no ambiente virtual de aprendizagem. Descobriu-se, então, que não basta a presença diária do mediador on-line (tutor) e do responsável pela disciplina na plataforma. Acompanhar de fato o educando no AVA, colocandose à disposição antes mesmo de ele manifestar-se, claro, é essencial e essa atitude produz reações e resultados altamente positivos. Notar que o tutor está on-line para qualquer eventualidade conforta, equilibra e incentiva o aprendiz.

Percebeu-se, entretanto, que existem outros fatores desencadeadores da sensação de solidão no ambiente. É muito importante que o aprendiz tenha, por exemplo, auxílio do docente para aprender a utilizar com confiança os recursos disponíveis, já que a insuficiência desse apoio agrava a sensação referida. O aluno espera do tutor a orientação necessária para se integrar ao grupo e se desenvolver no curso; se isso não acontece, ele se sente só e inábil para continuar.

A FATEC utiliza a plataforma Moodle, e, para realmente acompanhar o curso e a disciplina, é necessário que o estudante saiba elaborar o perfil, acrescentar foto, utilizar e consultar o fórum de dúvidas, enviar e responder mensagens privadas, visualizar o feedback na atividade de cada unidade de aprendizagem, localizar a atividade avaliativa e a não avaliativa, acessar as videoaulas, acessar os livros-textos e o material complementar. O tutor geralmente acredita que essas habilidades não 
necessitam ser consolidadas com suas turmas, em função de os alunos pertencerem a uma sociedade cada vez mais tecnológica. Constatou-se, porém, que as dúvidas persistem apesar disso. De modo a impedir que o graduando desista do curso, a orientação devida é sempre fornecida.

Foi exatamente no cumprimento da tarefa de ensinar os alunos a utilizar o aparato do AVA que se observou a resistência deles quanto à participação no fórum de dúvidas. Movidos por falsas crenças sobre o processo de aquisição da língua inglesa, os aprendizes, de modo geral, manifestam constrangimento quanto a compartilhar suas dúvidas e sugestões abertamente. O motivo detectado é basicamente um só: têm medo de errar e isso passar a ser do conhecimento dos colegas. Dirimir concepções arraigadas sobre a aprendizagem de línguas estrangeiras dos alunos, ainda que errôneas, é um processo lento. A despeito disso, a disciplina precisa ser ensinada, e há um cronograma a ser cumprido. Para que a interação acontecesse, portanto, houve o incentivo para a utilização das mensagens privadas e a eficácia da utilização do recurso na mediação on-line foi amplamente verificada.

Há que ser enfatizado o papel vital da comunicação escrita no processo. Embora no AVA existam os recursos tecnológicos específicos para propiciar a interação - chats, mensagens, fóruns, vídeos - muitas vezes o diálogo não acontece. A baixa adesão ao fórum é um exemplo disso. O tutor, pois, não pode prescindir da capacidade de utilizar a língua escrita com competência e gosto: encontrar as palavras, o tom, o arranjo sintático, o formato adequado para chamar o aluno para o estudo, ensinar-lhe o conteúdo e conduzi-lo à aprendizagem. Isso somente se consegue com o tempo dedicado à mediação, permanecendo na plataforma e usando esse trunfo em favor do aluno.

A plataforma Moodle permite que as mensagens privadas sejam trocadas em tempo real ou não e, ao clicar em Painel, é possível saber quais alunos estão on-line. Clicando no nome do aluno, aparece seu perfil quando pertencente a um dos grupos (turmas) do tutor, e, uma vez no perfil desse aluno, é possível enviar-lhe mensagens. Isso se tornou uma prática cotidiana para acompanhar os estudantes e saber de suas necessidades. Com a vantagem de a conversa acontecer somente entre o docente e o aprendiz. Sentindo-se resguardado para manifestar-se e participar da disciplina, ele permitiu que o tutor o conduzisse à aprendizagem, conforme será demonstrado mais abaixo.

\section{ALGUMAS PALAVRAS SOBRE A ESCRITA NA EaD E AS FALSAS CRENÇAS NO APRENDIZADO DE LÍNGUAS ESTRANGEIRAS}

Quando se menciona o papel da linguagem escrita na interação com o aprendiz na modalidade de ensino a distância, aceita-se que, nas interações 
presenciais, o professor sempre tem à disposição, além da linguagem escrita, a oral e a gestual. Sem estar fisicamente com o aluno, todavia, o docente de EaD necessita ter o domínio da escrita para se comunicar de fato com esse aprendiz. Cabral e Cavalcante (2010, p. 79) concordam com tal postulado, e afirmam que

[...] precisamos ficar atentos às maneiras como nos dirigimos aos nossos alunos nas diversas situações que surgem, pois de nossa linguagem escrita, principal instrumento de comunicação nas práticas educativas a distância, depende a eficácia na interação.

Assim sendo, o fato de o professor não estar presencialmente como o aluno, longe de significar um entrave, pode encorajar o mestre a buscar e a desenvolver determinadas habilidades de escrita, tais como saber selecionar a palavra, o tom, a síntese, a ênfase, o arranjo sintático e o formato ajustados a esse meio de ensinar e ao propósito da aula. Empregada com zelo, acredita-se que a escrita possa mesmo promover a afetividade, relevante e presente indubitavelmente na educação on-line, e com isso também concordam Lima e Machado (2010, p. 7).

Como, nesses cursos, as pessoas, geralmente, não têm a possibilidade de ver os gestos, os olhares, a expressão corporal dos colegas e professores, são as palavras e as imagens que transmitem os sentimentos. Devemos, então, estabelecer um paralelo entre a linguagem e a afetividade na educação on-line, a partir da percepção de que ambas são inseparáveis nos cursos de $E A D$, e de que o sucesso das mesmas leva ao consequente sucesso do processo ensino/aprendizagem.

A alusão ao tema das emoções na interação a distância leva à discussão das razões que explicariam o constrangimento experimentado por muitos alunos para expor suas dúvidas e sugestões no fórum de dúvidas. O medo da exposição de erros eventuais é a percepção mais comum para não aderirem ao recurso com a mesma disposição como o fazem em relação às mensagens privadas. Conforme pesquisas do Prof. Fabio Madeira, falsas crenças dos alunos (e mesmo de professores) sobre o processo de aquisição da língua inglesa impedem que se desenvolvam satisfatoriamente na disciplina.

As crenças trazidas pelos alunos (e pelos professores também) nem sempre estão explícitas em seus dizeres, portanto, são de difícil observação. São formadas por uma configuração complexa de diversos fatores, entre os quais questões afetivas e socioculturais, hábitos arraigados e conceitos adquiridos, fatores esses estreitamente relacionados com o contexto sociocultural e com experiências pregressas de ensino e aprendizagem. (MADEIRA, 2019, p. 248)

Confirmam o que diz o pesquisador as palavras de um aluno da disciplina Inglês II, no ano de 2017. Apresenta-se abaixo o diálogo mantido por mensagem privada sobre o uso dos fóruns: 


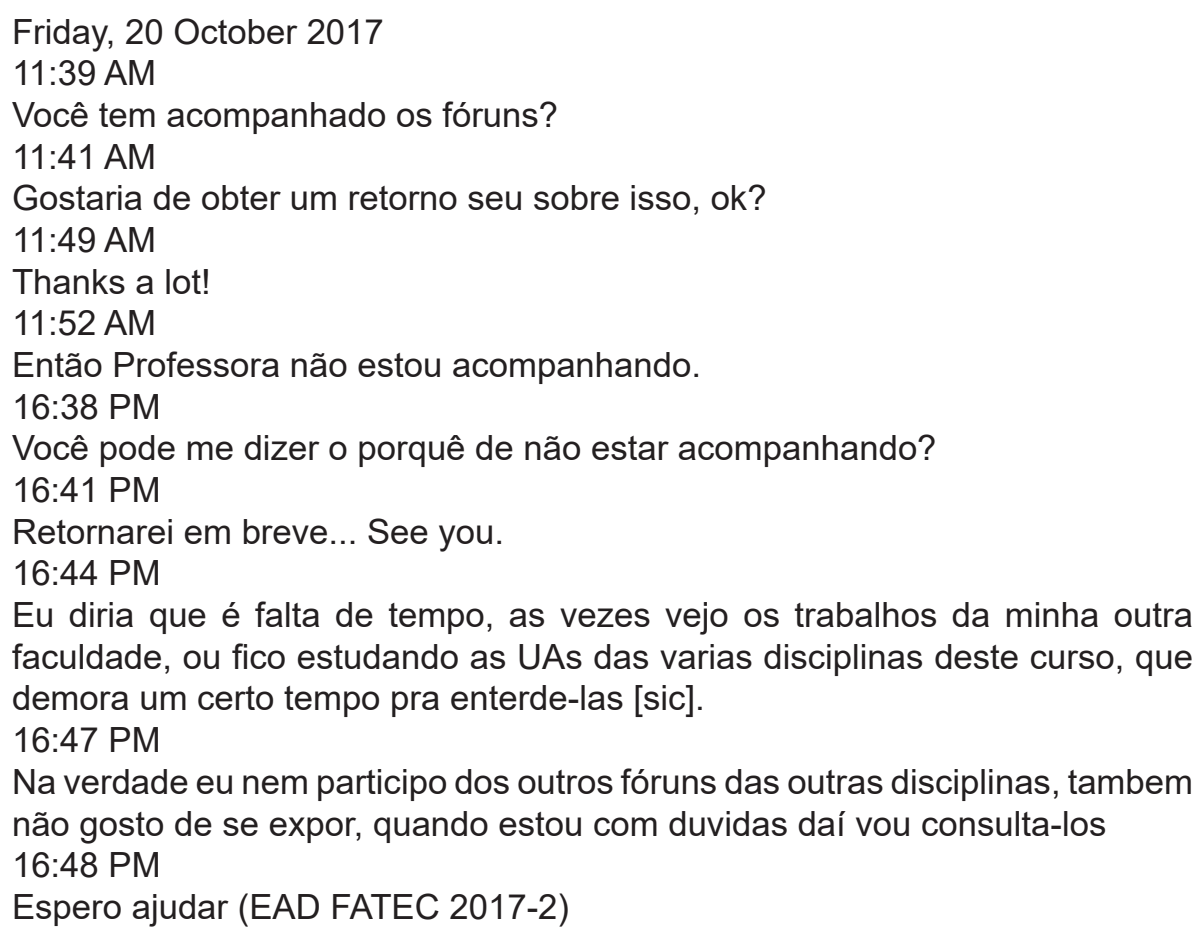

Apesar de o aluno alegar que não gosta de se expor, ele não deixa claro se é pelo receio de errar, mas isso fica subentendido. Na sequência, apresenta-se a conclusão da conversa. Perceba-se que se estimula a participação com a menção ao recurso das mensagens privadas como alternativa para a provável convicção dele sobre erro:

\section{6:48 PM}

Ok, Jose Laurindo! Sim, seu depoimento ajudou muito. É necessário saber se o aluno está acessando todo o material disponível, pois disso depende o aprendizado efetivo. Assim, peço que você se anime a participar dos fóruns, inclusive do "Let's talk about...". Meus comentários são enviados por mensagem privada,ok?

Have a splendid weekend!

Teacher Denise Bertolucci (EAD FATEC 2017-2)

O fórum "Let's talk about..." referido acima era temático e integrou o AVA da disciplina Inglês II até o fim de 2017. Em 2018, por causa da baixíssima adesão dos alunos, mesmo com constantes incentivos para sua utilização, foi retirado da plataforma, permanecendo somente o fórum de dúvidas. A troca de mensagens privadas com os aprendizes, em função das qualidades já apontadas, sempre teve e ainda tem aceitação maior, garantindo a aprendizagem efetiva da língua. Por isso é eficaz. É importante dizer também que, pelo meio em questão, sempre é possível ter um feedback mais confiável dos alunos. Justamente por não estarem expostos, costumam ser mais sinceros e até mais soltos: 


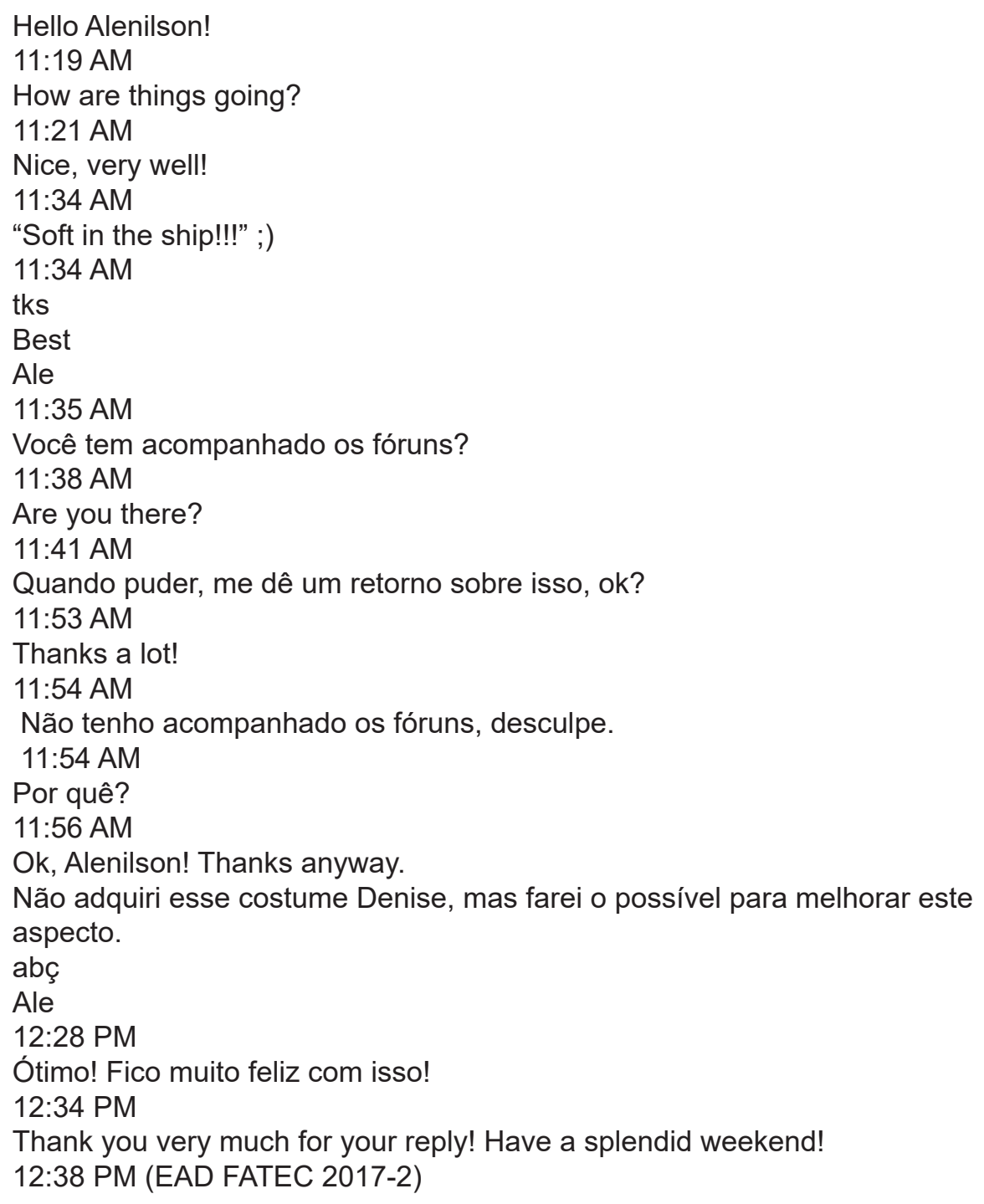

O aluno é franco e confessa não acompanhar os fóruns, porém mostrase disposto a tentar fazer isso. É alentadora, todavia, a espontaneidade revelada no início da interação. Ele não se limita a responder ao cumprimento, e o faz acrescentando uma expressão idiomática, acertadamente posta entre aspas para indicar o significado específico que aquelas palavras possuem juntas, diferente do que cada uma possui se considerada isoladamente. $\mathrm{O}$ emprego da preposição necessitou de um esclarecimento posterior, mas, ainda assim, a abertura do estudante para o aprendizado da língua foi amplamente facilitada pela mensagem privada. Será que o aprendiz teria tal desenvoltura no fórum? Talvez não. Antes de se discutirem outras interações, é oportuno tratar do método adotado.

\section{ALGUMAS PALAVRAS SOBRE A METODOLOGIA EMPREGADA}

Este trabalho é resultado da experiência desta pesquisadora com a docência em EaD nos últimos cinco anos, inicialmente como mediadora (tutora) e depois 
como responsável pelas disciplinas Inglês I, Inglês II e Inglês III, no curso Gestão Empresarial - EaD, da Faculdade de Tecnologia do Estado de São Paulo - FATEC. Por conseguinte, utiliza-se como metodologia de pesquisa o relato de experiência.

Nesta síntese dos principais resultados evidenciados ao longo dos anos de experiência com a EaD no curso referido, expõem-se e discutem-se primeiramente exemplos de interações instauradas entre a mediadora on-line (esta pesquisadora) e o aprendiz. O profissional mediador on-line (tutor), sabe-se,

[...] com base no material elaborado pelo professor autor [formador], orienta e auxilia o aluno nas discussões teóricas, esclarece dúvidas, encaminha atividades e avalia o processo ensino-aprendizagem. Como na modalidade a distância a presença física do professor [autor] é dispensada, cabe ao tutor assumir esse papel. Assim, enquanto a imagem do professor [autor] aparece de forma difusa e virtual, a do tutor se revela nítida e real, pois é este que estabelece o contato direto com o aluno. (ZAVAM, 2013, p. 216-217).

Na FATEC existe ainda, é necessário elucidar, a figura do professor responsável por disciplina (RD). Como a designação antecipa, esse professor responde pela disciplina: orienta os mediadores on-line, elabora as atividades avaliativas do ambiente virtual e as avaliações presenciais, e ainda atualiza e revisa o material didático disponível na plataforma.

Diferentemente do professor formador, o RD nem sempre é o autor do material de estudos das unidades de aprendizagem (lições ou módulos) que constituem sua disciplina. Ele também acompanha o trabalho de mediação diariamente. Por isso, foi possível a esta pesquisadora interagir com os alunos também nessa função. Assim, nos momentos de interação seguintes, há os resultados obtidos nas funções de mediadora on-line e de responsável pela disciplina Inglês.

\section{EFICÁCIA DA MENSAGEM PRIVADA NA MEDIAÇÃO ON-LINE}

\subsection{Exemplos como mediadora on-line}

A troca de mensagens privadas que segue é a primeira de uma série com a mesma aluna do Inglês II, no ano de 2017.

Tuesday, 8 August 2017

Hello Giselle! How are you doing?

10:44 AM

Hello, teacher! I'm fine and you?

13:55 PM

Have a great afternoon! :D

13:57 PM

Thank you! The same to you. If you have any questions, please let me know. 14:07 PM

As atividades avaliativas começam a partir da semana que vem (UA 03)? 
Pois ainda não disponibilizaram o cronograma de atividades na plataforma... 14:31 PM

Isso mesmo. Assim que tivermos o cronograma, vocês serão informados.

14:41 PM

Thank you teacher

14:45 PM [...] (EAD FATEC 2017-2)

Observe-se que ela, ao ser estimulada a iniciar a conversação respondendo a um cumprimento, esquiva-se inicialmente. Mais tarde, porém, no mesmo dia, possivelmente depois de certificar-se de uma possibilidade aceitável de resposta, não apenas responde, como alimenta a interação em língua inglesa. A mensagem privada garantiu-Ihe a possibilidade de postergar a resposta, mas essa foi dada e o aprendizado aconteceu. Na conversa seguinte, a aluna acessa o ambiente no sábado e deixa uma pergunta. Por ser um dia da semana em que a mediadora on-line não está presente, a resposta é dada na segunda-feira:

Saturday, 2 September 2017

Teacher... Can you help me?!

No semestre passado aprendemos a colocar o -ING.

Por exemplo nesse texto: "we selected some important tips for startING and endING telephone conversations. "A Tradução seria: nós selecionados alguns dicas importantes para INICIAR e TERMINAR a conversa telefônica." Por que foi inserido o ING sendo que na hora da leitura não lemos como iniciando e terminando?

Já vi isso em vários textos e não compreendi... Se puder me auxiliar, eu agradeço.Abraços.

Have a excellent Saturday!

14:39 PM

Monday, 4 September 2017

Hello Giselle! How are you doing? A razão está na construção do exemplo que você forneceu: substantivo (tips) + preposição (for) + -ing. Esta é a norma:

"We selected some important tips for startING and endING telephone conversations."

Veja outros exemplos:

"Put those clothes in a pile for washing."

"There are good reasons for eating a lot of fruit."

Exemplos com outras preposições:

"She came within two seconds (substantivo) of (preposição) beating the world record."

"If you have any thoughts or interests (substantivo) about (preposição) studying abroad..."

Espero ter ajudado.

Wishing you a nice week,

Teacher Denise Bertolucci

10:45 AM

Ah sim, agora entendi... Thank you :D

10:53 AM

You're welcome!

10:59 AM (EAD FATEC 2017-2)

Em razão de o aprendizado na EaD acontecer ininterruptamente, isto é, o aluno não precisa pausar seus estudos no fim de semana, se não quiser, a estudante 
busca o conteúdo no sábado e solicita esclarecimentos diretamente à mediadora. $\mathrm{Na}$ segunda-feira pela manhã, obtém a resposta. $\mathrm{O}$ recurso, pois, propiciou à aluna organizar a pergunta com um detalhamento que talvez não quisesse compartilhar com os colegas. O arranjo obtido por ela, no entanto, facilitou a elucidação e o aprendizado ocorreu. Na sequência, a mesma aluna toma a iniciativa da abordagem, incorporando o cumprimento utilizado por esta pesquisadora numa interação apresentada anteriormente:

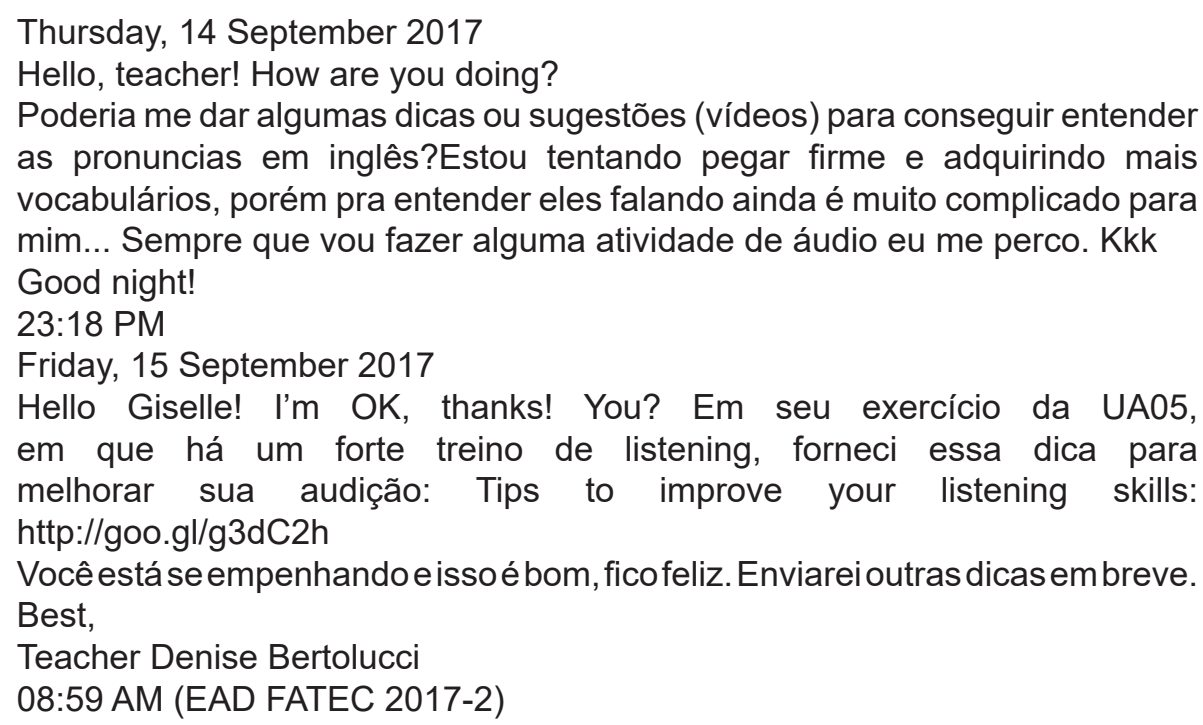

É gratificante constatar o progresso da estudante, que já se sente confortável inclusive para avaliar sua aprendizagem, permitindo a ação da mediadora no atendimento da necessidade exteriorizada. Abaixo, a troca de mensagens privadas patenteia o desenvolvimento da aluna na disciplina e sua gratidão por isso:

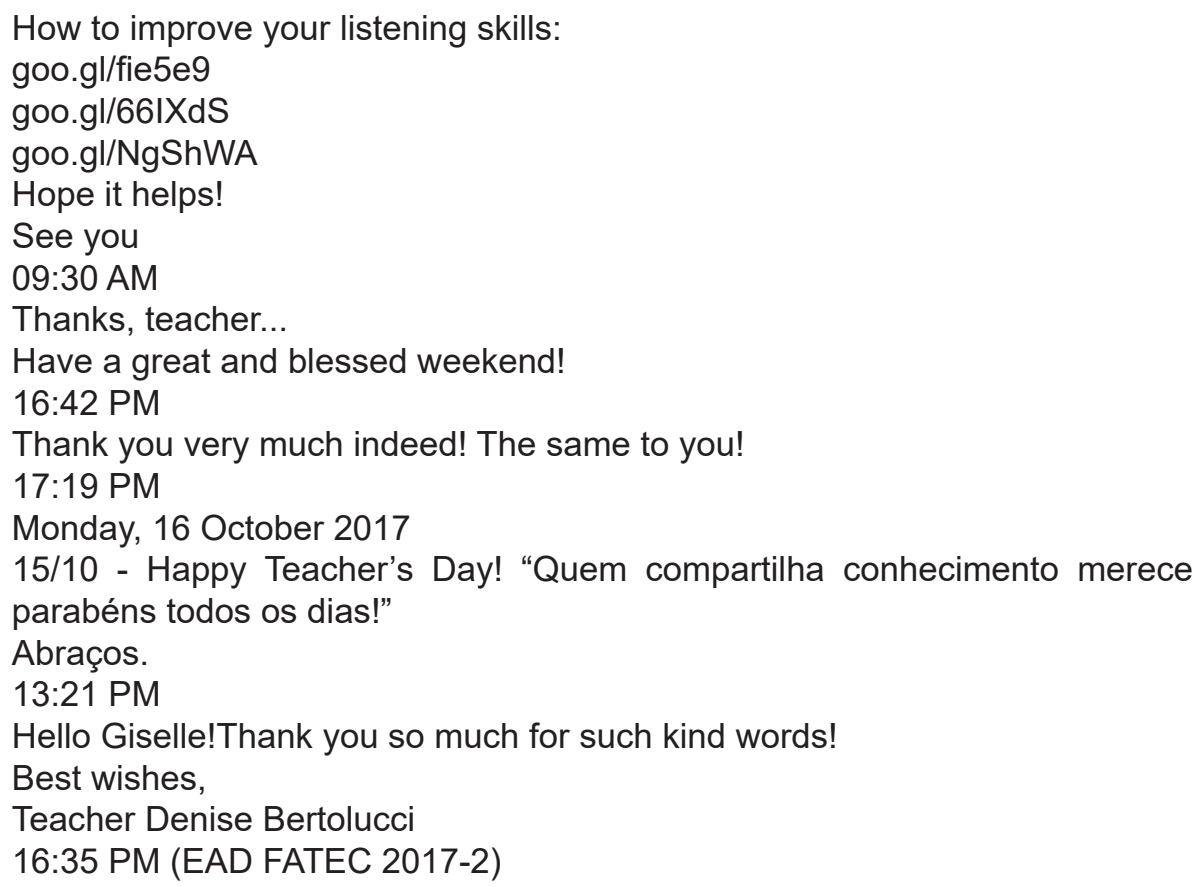


Na sequência, apresentam-se e comentam-se interações ocorridas ainda no ano de 2017, com uma outra aluna da disciplina Inglês II:

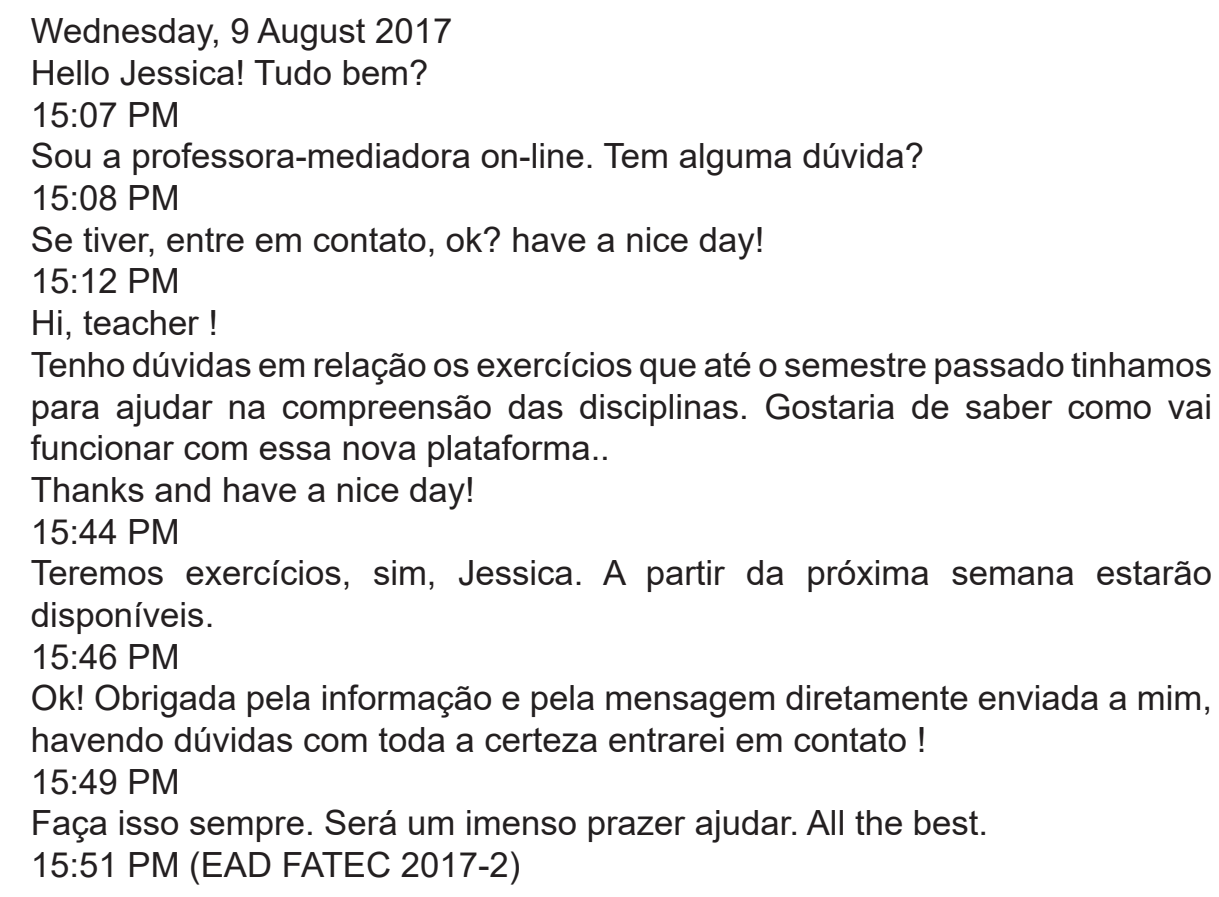

Mesmo que a dúvida da aluna não envolva o conteúdo da disciplina, mas trate de um aspecto operacional, é clara a satisfação dela com a convocação para uma conversa privada, em que pode se manifestar livremente. Na interação acima, a aluna responde ao primeiro estímulo da mediadora on-line depois de pouco mais de meia hora. Obtendo a resposta rápida a seu questionamento, no entanto, sente-se agradecida, como se constata, e ao longo dos meses, segue cumprindo suas tarefas sem problemas. Em setembro do mesmo ano, há a comprovação de seu sucesso no acompanhamento da disciplina:

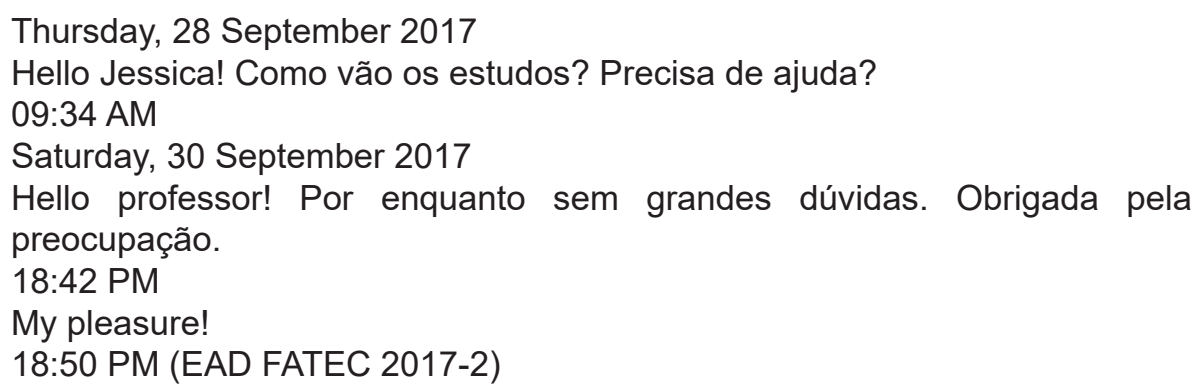

A resposta da aluna mais uma vez chega depois de decorridas horas do primeiro estímulo à interação. Ela teve um período assíncrono para encontrar uma forma apropriada de se dirigir à mediadora atuante no ensino superior: Professor. $\mathrm{O}$ recurso da mensagem diretamente dirigida a ela novamente recebe uma expressão de gratidão. Dada a certeza de estar livre de qualquer julgamento de colegas, caso 
quisesse expor alguma dúvida, depreende-se que a graduanda possui mesmo o perfil esperado do aluno de EaD. Prefere resolver de forma autônoma o que considera mais simples, não representando uma "grande dúvida". Esse seria o caso, pode-se inferir, de algo que a impedisse de avançar nos estudos. Raciocínio bastante acertado, sem dúvida.

A comprovação objetiva da eficácia da mensagem privada na mediação on-line no ano de 2017 está nos gráficos oferecidos abaixo. Acompanhem-se os resultados das duas primeiras atividades avaliativas de 2017.

Figura 1 - Atividade Avaliativa 1 - $1^{\circ}$ semestre de 2017 (Inglês II).

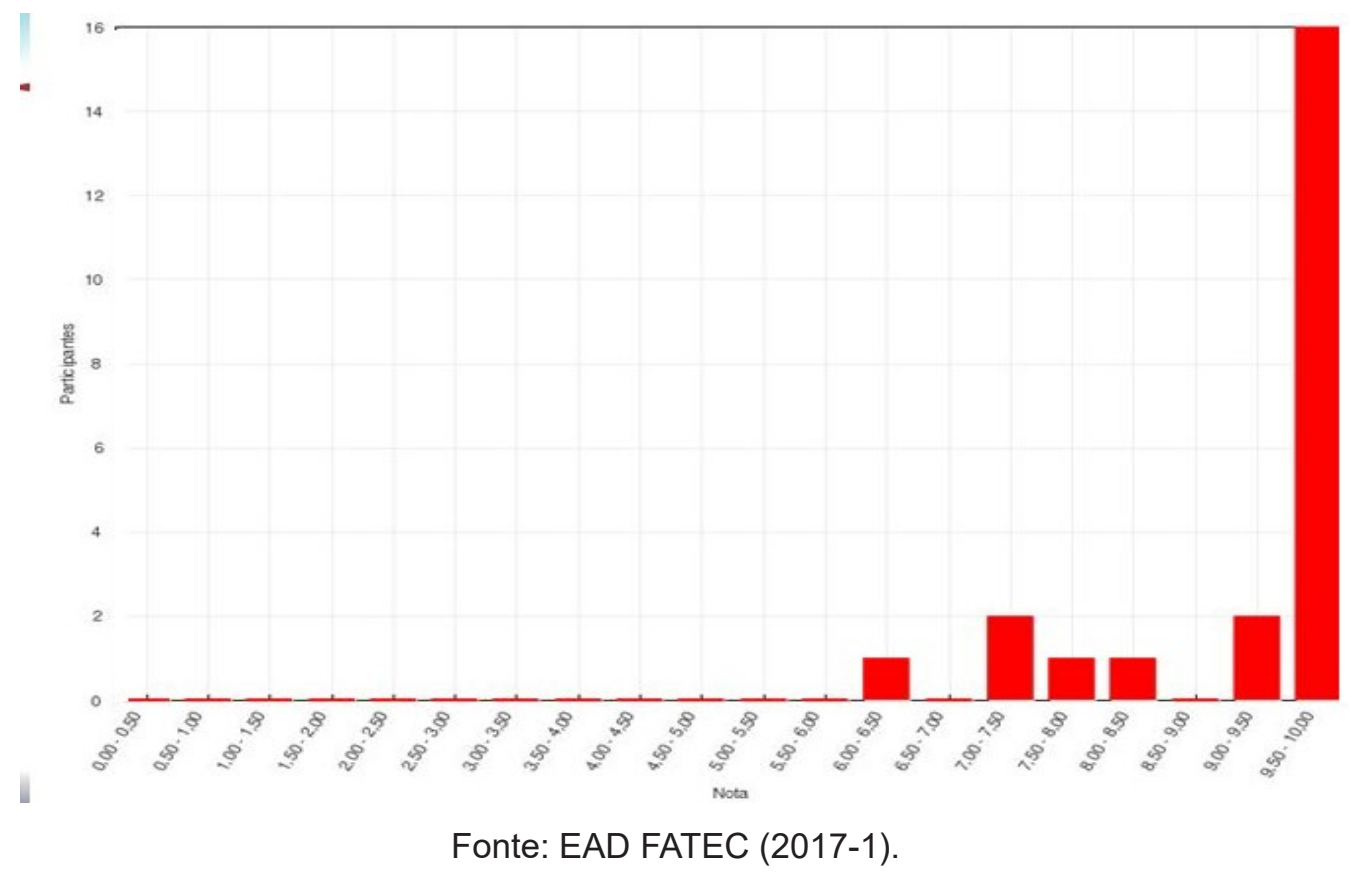

Não é difícil perceber que as notas altas, representadas por 9,5-10,00, preponderam. Há um índice bem menor de notas nas faixas de 9,00-9,50 e 7,007,50 . As mais baixas formam um número ínfimo, e mesmo aquelas da faixa 6,006,50 não significam um desempenho preocupante, uma vez que se situam na média indispensável para a aprovação. Pode-se concluir, com a visualização do primeiro gráfico, que o aprendizado se deu e o recurso das mensagens privadas é de fato um grande aliado no alcance de notas satisfatórias.

Verifiquem-se, na sequência, os resultados organizados no segundo gráfico. Trata-se também das notas obtidas na disciplina Inglês II no ano de 2017. Os dados ora apresentados referem-se à segunda atividade avaliativa. Como praticamente se repetem as informações, é escusado, crê-se, fornecer novos comentários. Diz-se apenas que as notas altas da faixa 9,5-10,00 permanecem com maior incidência. 
Figura 2 - Atividade Avaliativa $2-1^{\circ}$ semestre de 2017 (Inglês II).

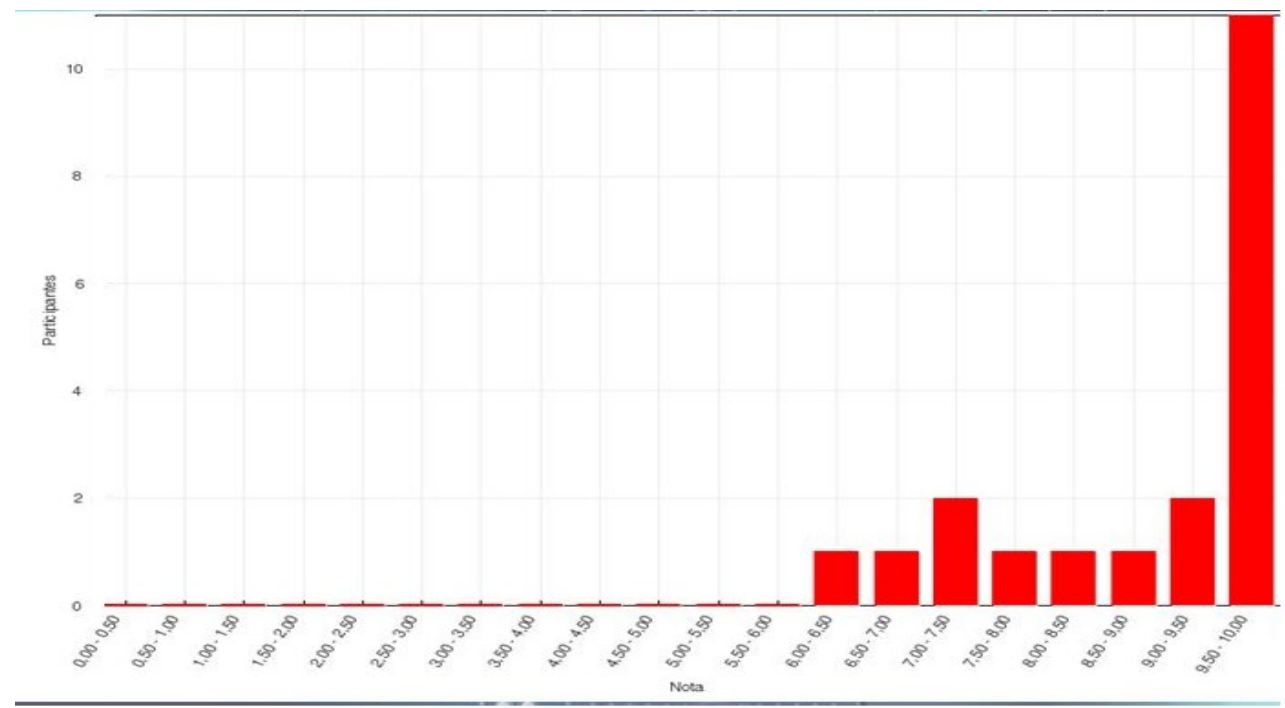

Fonte: EAD FATEC (2017-1).

Concluída a exemplificação da eficácia das interações estabelecidas entre mediadora on-line e alunos, é tempo de se discutir o exemplo da mediação instaurada entre a professora responsável por disciplina e os graduandos. A seleção de apenas um exemplo dessa modalidade explica-se por dois motivos. Em primeiro lugar, as situações de trocas com os alunos tornam-se menos frequentes nessa função. Em segundo, fez-se a opção pela ocorrência mais significativa, cujo efeito foi rápido, porém salutar.

\subsection{Exemplo como professora responsável por disciplina (RD)}

$\mathrm{Na}$ interação como RD, destaca-se um diálogo que menciona o roteiro concebido depois de se averiguar que os aprendizes não estavam lendo o material de estudos para realizar as atividades avaliativas do ambiente virtual ou estavam empreendendo uma leitura insuficiente para isso. Houve, portanto, a necessidade de ensinar-lhes a corrigir a falha. $O$ roteiro foi enviado a todos os estudantes por meio do endereço de e-mail pessoal deles. Graças às mensagens privadas e ao acompanhamento em tempo real do cumprimento da atividade pelo aluno no AVA, viabilizou-se o reenvio do roteiro tão logo se constatou um desempenho insatisfatório em sua primeira tentativa de realização. É o que se observa abaixo:

Wednesday, 6 March 2019

Hello Fernando!

Reveja a questão 3.

Profa Denise Bertolucci

11:49 AM

Hello Fernando!

Não conclua a segunda tentativa da Atividade Avaliativa 1 (Inglês 
III) sem antes ler o material que enviei para seu email. Tratase de um roteiro para auxiliá-lo a melhorar seu desempenho. Leia com atenção e obtenha a nota de que sei que você é capaz. Thank you,

Denise Bertolucci

Responsável pela disciplina Inglês III

11:56 AM

Fernando, enviei o Roteiro novamente.

Aproveite e melhore sua nota.

Prof $^{a}$ Denise Bertolucci

12:01 PM

Ok. Thanks.

12:03 PM

My pleasure!

12:04 PM

Congratulations on your excellent result (Atividade Avaliativa 1 - Inglês III)! I knew you could do it!

Many thanks,

Profa Denise Bertolucci

18:19 PM (EAD FATEC 2019-1)

Como são duas tentativas, antes que realizasse a segunda, houve uma conversa reservada com esse aluno com o objetivo de lembrá-lo da existência daquele material concebido para auxiliá-lo a ter uma boa performance na atividade, e o aviso para que o buscasse na caixa de emails. O resultado desse esforço foi o esperado: os conteúdos foram apreendidos pela maior parte dos alunos e a incidência de notas altas se fez notar novamente. Acompanhem-se, na tabela abaixo, os dados do número de alunos por faixas de notas na Atividade Avaliativa 3, da disciplina Inglês III, no ano de 2019:

Figura 3 - Atividade Avaliativa 3 - $1^{\circ}$ semestre de 2019 (Inglês III).

$\begin{array}{ll}9,50-10,00 & 110 \\ 7,50-8,00 & 37 \\ 5,00-5,50 & \\ 2,50-3,00 & \\ 3 \\ 0,00-0,50 \ldots \\ \end{array}$

Fonte: Elaborado pela autora.

\section{CONSIDERAÇÕES FINAIS}

A transcrição dos diálogos mantidos por mensagem privada destacados no item antecedente confirmam que o uso do recurso, aliado ao emprego cuidadoso da linguagem escrita nas interações, afiançou o processo ensino/ 
aprendizagem do Inglês no curso Gestão Empresarial - EaD, da Faculdade de Tecnologia do Estado de São Paulo - FATEC e proporcionou até mesmo a instauração de afetividade na mediação.

Com a utilização desse meio, pôde-se dar continuidade às aulas e ministrar os conteúdos, ainda que muitos dos estudantes trouxessem para o ambiente virtual convicções infundadas sobre a aprendizagem de línguas estrangeiras. A efetividade das mensagens privadas na mediação on-line comprovou-se de forma patente com a exibição dos gráficos e tabela, em que sobressaíram as notas da faixa 9,5-10,00.

Fica, assim, demonstrada a eficácia da mensagem privada na mediação on-line, e a manifestação entusiástica da RD no final da última interação apresentada é a prova definitiva do sucesso desse aparato na educação a distância do curso em foco.

\section{REFERÊNCIAS}

CABRAL, Ana. I. Tinoco; CAVALCANTE, Alessandra F. Linguagem escrita. In: CARLINI, Alda Luiza; TARCIA, Rita M. Lino. 20\% a distância e agora? São Paulo: Pearson Education do Brasil, 2010.

FACULDADE DE TECNOLOGIA - EAD FATEC CENTRO PAULA SOUZA - 20191. Disponível em: http://eadfatec.cps.sp.gov.br/moodle20191/course/view.php?id=33 Acesso em: 30 jun. 2020.

FACULDADE DE TECNOLOGIA - EAD FATEC CENTRO PAULA SOUZA - 2017-2.

LIMA, Catley Santos; MACHADO, Michelle Jordão. As letras falam: afetividade e escrita em cursos de Educação a Distância. $3^{\circ}$ Simpósio Hipertexto e Tecnologias na Educação: Redes Sociais e Aprendizagem. Anais Eletrônicos. 2010.

MADEIRA, Fabio. Perspectivas de alunos principiantes sobre fatores facilitadores do processo de aprendizagem de língua estrangeira. Revista CBTecLE, v. 1, n. 1, p. 246259, 2019. Disponível em: https://revista.cbtecle.com.br/index.php/CBTecLE/issue/ view/v.1\%2Cn.1\%20\%282019\%29. Acesso em: 30 jun. 2020.

ZAVAM, Aurea. Da escrita à revisão: o processo de produção de material para EaD. In: ARAÚJO, Júlio; ARAÚJO, Nukácia (Orgs.). EaD em tela: docência, ensino e ferramentas digitais. Campinas: Pontes Editores, 2013. p. 209-238. 


\section{BIOGRAFIA DA AUTORA}

DENISE MARIA DE PAIVA BERTOLUCCI - Graduação em Letras - Português/Inglês (1985), Graduação em Letras - Alemão (1986), Mestrado (1992), Doutorado (2005) e Pós-Doutorado (2012) em Letras pela Universidade Estadual Paulista Júlio de Mesquita Filho (UNESP). Atualmente é Responsável pelas Disciplinas Inglês II, Inglês III e Comunicação e Expressão no curso Gestão Empresarial, e atua como autor de reoferta da disciplina Inglês $V$ no curso Gestão Pública, ambos na modalidade EaD, na Faculdade de Tecnologia do Estado de São Paulo (FATEC) e na Universidade Virtual do Estado de São Paulo (UNIVESP). Tem experiência nas áreas de Letras e Educação, atuando nos seguintes temas: ensino presencial e a distância, mediação on-line, línguas portuguesa e inglesa, metodologia da pesquisa científica, literatura infantil, literaturas de língua portuguesa e língua inglesa, narrativa, Monteiro Lobato, periódico Revista do Brasil.

Data de recebimento: 01/09/2020

Data de aprovação: 23/10/2020 